Fecha de recepción: noviembre 2020

Fecha de aprobación: diciembre 2020

Fecha publicación: marzo 2021

\section{Dossier gráfico de El Eternauta}

Colectivo artístico Un Faulduo ${ }^{(1)}$

(1) Un Faulduo es un colectivo de investigación y experimentación alrededor del campo de la historieta, formado por Nicolás Daniluk, Ezequiel García, Nicolás Moguilevsky y Nicolás Zukerfeld. En un recorrido interdisciplinario que abarca las artes visuales, el cine, la música, las artes escénicas y la literatura, el grupo realizó exposiciones, intervenciones urbanas y acciones performáticas en el Fondo Nacional de las Artes, C. C. San Martín, UBA, Biblioteca Nacional, ArteBA, Universidad Di Tella, Club Editorial Río Paraná (Rosario), C. C. Borges, CCK, CNB - Casa del Bicentenario, C. C. Recoleta y Oficina 26 (Rosario), entre otros espacios. El colectivo también edita una revista en papel que lleva 11 números y mantiene, desde su aparición en 2005, un sistema de rotación de directores: cada número es dirigido por un miembro diferente del equipo, lo que obliga a cambios de formato, contenido y técnica. En el 2015, Un Faulduo publicó "La historieta en el (Faulduo) mundo moderno" (Tren en Movimiento Ediciones, Argentina; Ediciones Marmotilla, España, 2018), libro inspirado en el célebre texto de Oscar Masotta "La historieta en el mundo moderno" (1970), en el que el grupo se propuso pensar la relación entre el lenguaje de la historieta y la forma del ensayo. Durante 2017 y 2018, Un Faulduo dictó un taller y expuso su trabajo en el marco de la muestra colectiva "Oscar Masotta. La teoría como acción", curada por Ana Longoni (MUAC - Museo Universitario Arte Contemporáneo, UNAM, México; MACBA - Museo de Arte Contemporáneo, Barcelona, España; Parque de la Memoria, Buenos Aires, Argentina).

En 2019, el grupo realizó la perfomance "Desde hoy: El eternauta" como parte de la exposición "Breccia 100" en la Casa Nacional del Bicentenario; curó la muestra "Fuera de registro: un mapa imaginario de la historieta argentina" en el CCK (incluyendo a 23 historietistas argentinos mediante los cuales se vislumbra un posible recorrido alternativo por la historia del cómic en nuestro país) y participó de "Palabra de Oesterheld", gran retrospectiva dedicada a la carrera profesional de Héctor Germán Oesterheld, en la Biblioteca Nacional Mariano Moreno de Buenos Aires.

Actualmente el grupo trabaja en un nuevo proyecto, "Desde hoy: El Eternauta", futuro libro de 80 páginas que dialoga, reescribe e interviene el mítico No 202 de la revista "Gente" en el que apareció por primera vez la historieta "El Eternauta" de Oesterheld-Breccia en 1969. 


\section{I.}

El Eternauta es una historieta argentina creada por Héctor G. Oesterheld con dibujos de Francisco Solano López, publicada inicialmente en la revista Hora Cero entre 1957 y 1959 y considerada, retrospectivamente, como una de las primeras novelas gráficas. Cuenta la historia de un grupo de hombres y mujeres liderados por Juan Salvo (El Eternauta) que combaten una misteriosa nevada mortal que acecha el planeta. Esta versión fue rápidamente interpretada y resignificada alegóricamente, lo que la convirtió, como a ninguna otra historieta, en un clásico de la literatura universal. ¿Novela de anticipación, aventura pulp, relato distópico? Todo eso al mismo tiempo.

Diez años más tarde de la publicación del original, el 29 de mayo de 1969, en el № 201 de la revista Gente (que sólo brevemente había incluido historietas en sus páginas) se anuncia: Desde hoy: El Eternauta. Fundada en 1965, Gente (cuyo nombre completo es Gente y la Actualidad) era (y lo sigue siendo) un medio gráfico argentino centrado en temas "del corazón”. Con un diseño similar a la española ¡Hola! o la norteamericana People, en sus páginas suelen desfilar los escándalos del mundo del espectáculo y retratos del llamado jetset, mezclados con noticias políticas o de relevancia internacional. Sin embargo, siendo la revista de más éxito de ventas, desde fines de los ' 60 hasta principios de la década del ' 80 se convirtió, abiertamente, en un órgano de difusión de las ideas más reaccionarias del país, llegando a tener denuncias que afirman que participó en la construcción de una imagen favorable de la última dictadura militar argentina. Esto generó que Gente se convirtiera, mucho tiempo después, en un símbolo de aquello que se denominó la "banalidad del mal". Ahora la "prensa rosa" se mezclaba con el terrorismo de Estado y la muerte.

Pero a finales de la década del ' 60 , nada de esto se veía claramente y solo había un rancio aroma de la oscuridad que se aproximaba. Gente, entonces, en un gesto que intentaba elevar intelectualmente la calidad estética de sus páginas y mostrarse abierta, plural y "contradictoria", comienza a editar la segunda versión de El Eternauta, a tres páginas por semana, con la idea de que se extendiera por aproximadamente un año.

Para esta nueva versión, Oesterheld reescribe el guion reubicando la invasión en América Latina y el dibujo queda a cargo de Alberto Breccia. La historieta potenció a Breccia hacia su mayor arco de experimentación, pero rápidamente llegaron las críticas por el tono sombrío y la extrañeza del dibujo (los lectores la consideraban "inexplicable" y "confusa"), provocando que Gente decida abreviar la historieta, pida disculpas a sus lectores y suspenda su publicación.

\section{II.}

Breve, fallido y explosivo, El Eternauta de 1969 termina siendo una mancha en el medio de una revista que, intentando estar "a tono" con los años que corrían, no soporta el peso de la tinta y una nueva política de las formas cayendo en su propia trampa. Como mencionan Carlos Trillo y Guillermo Saccomano: 
El Eternauta de Oesterheld y Breccia es una obra de arte maldita. Es un relato lúcido, que arranca lenta y puntillosamente el trazado de una metáfora: la invasión. En la medida en que el relato profundiza en las contradicciones de un grupo humano que debe actuar, pensar y volver a actuar siempre en grupo para defender su condición humana, el editor responsable de la revista Gente (...) decide abortarla con final precipitado.

La compleja convivencia entre dos materiales, en principio opuestos, nos resulta clave para entender las tensiones entre historieta y cultura popular, historieta y arte contemporáneo, historieta y política. El nuevo texto de Oesterheld y el dibujo de Breccia se convierten de esta manera en los principales promotores de esta fricción, quebrando el lenguaje de la historieta y -en el caso de Breccia- anticipando técnicas que él mismo desarrollará en sus siguientes trabajos.

Estudiar El Eternauta por fuera de su contexto original excluye el diálogo que mantuvo con las páginas de Gente, entre televisores en venta, revueltas estudiantiles y festivales de cine. El montaje involuntario entre la historieta y el resto de la revista también expone, inconscientemente, un clima de época: el comienzo del período de los grupos guerrilleros armados en el continente (y su posterior exterminio por parte de las dictaduras que tomaron el poder en América Latina) y los cambios culturales post mayo del '68. ¿Pero cómo revelar aquello que se nos presenta entre líneas, secreto e invisible?

\section{III.}

Partiendo de la aparición de las tres primeras páginas de El Eternauta de Oesterheld-Breccia en Gente realizamos, desde el presente, una lectura crítica intentando iluminar las tensiones suscitadas con los materiales diversos y laterales que la revista publicó en ese número.

Lo que se leerá a continuación son algunos fragmentos que forman parte del libro Desde hoy: El Eternauta, proyecto que continúa con el trabajo de resignificación comenzado en La historieta en el (Faulduo) mundo moderno (Tren en Movimiento Ediciones, Buenos Aires, 2015; Ediciones Marmotilla, Madrid, 2018) basado en La historieta en el mundo moderno (Paidós, Buenos Aires, 1970), de Oscar Masotta. Cruzando las Mémoires de Guy Debord y Asger Jorn y el Álbum de Hannah Höch con la teoría estética de Aby Warburg, Desde hoy: El Eternauta no intenta una lectura total y cerrada, sino una intervención incompleta y fragmentaria, como el trazo experimental de Alberto Breccia.

Desde hoy: El Eternauta cuenta la melancólica historia de uno o varios hombres y mujeres deambulando como fantasmas o Eternautas en las nieves del tiempo. Hombres y mujeres entre el fin de una década y el comienzo de otra. Hombres y mujeres perdidos entre la política y el espectáculo, entre la violencia del Estado y un estado de violencia. Pero también la historia de una mancha, oscura, profunda; la de la sangre de los muertos, la de los escritos de Oesterheld o la tinta de Breccia, que salpicarán cada pliego, texto y margen de la revista, haciendo estallar no solo la historieta, sino también el pasado, el presente y el futuro. 


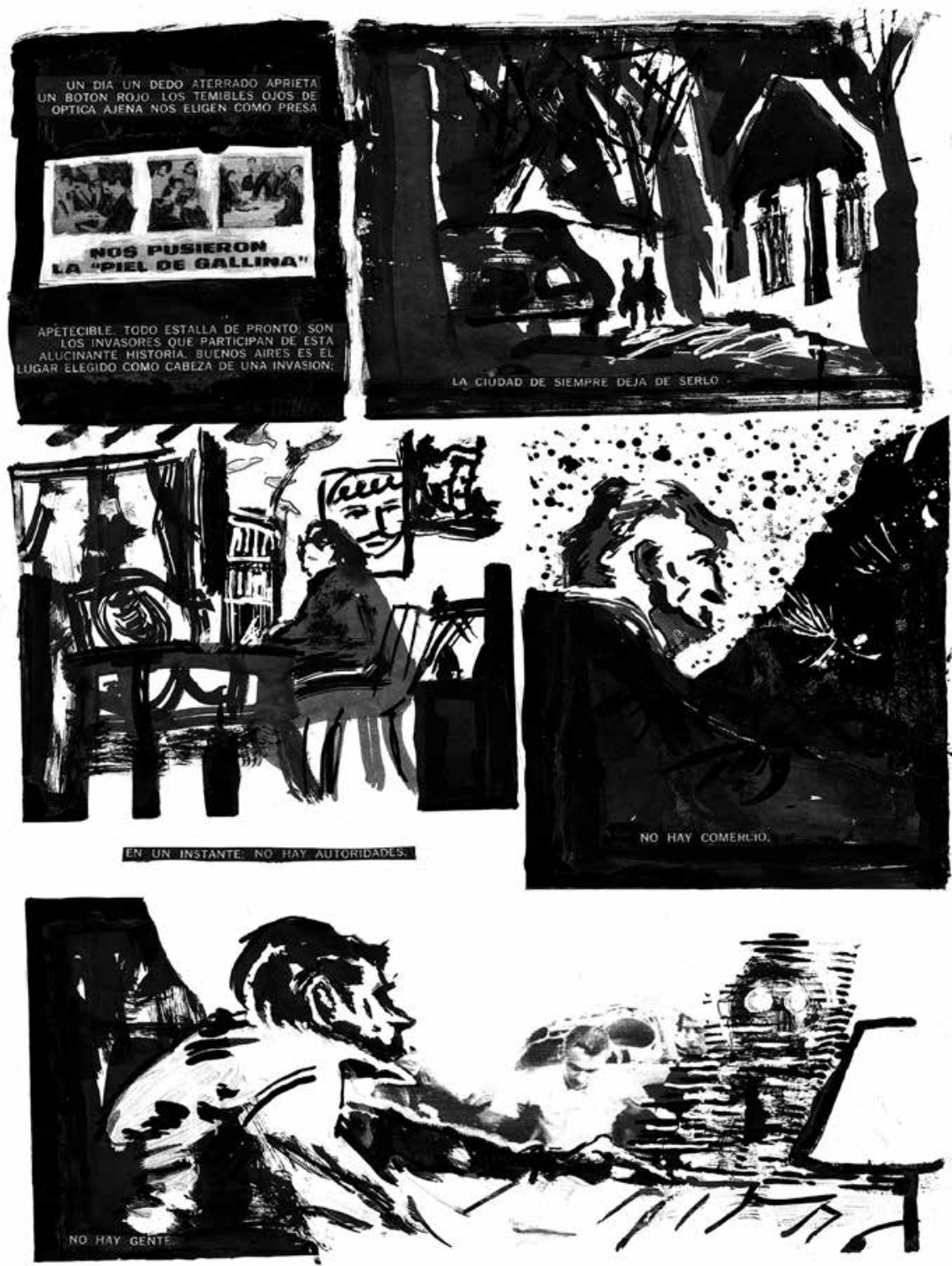




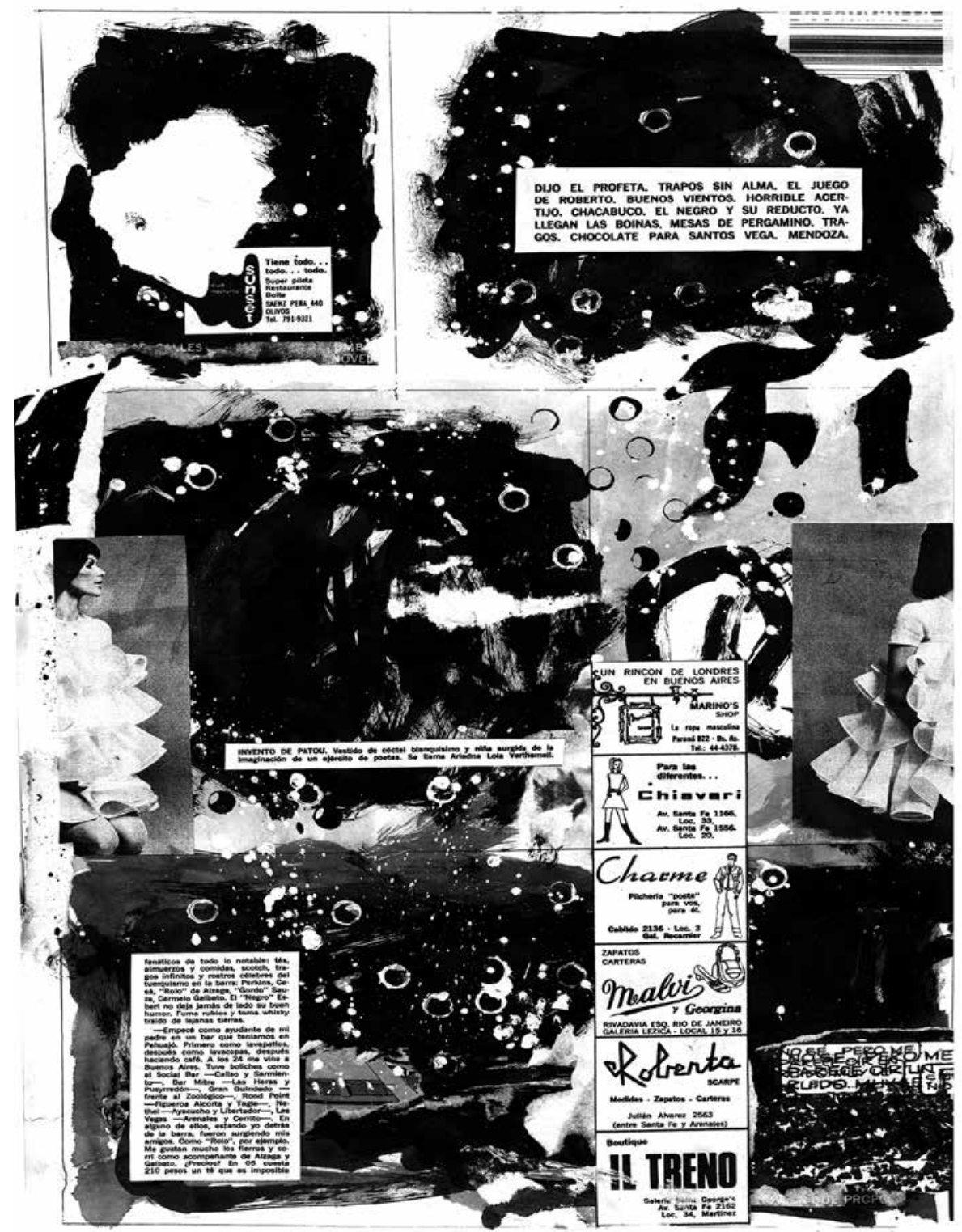




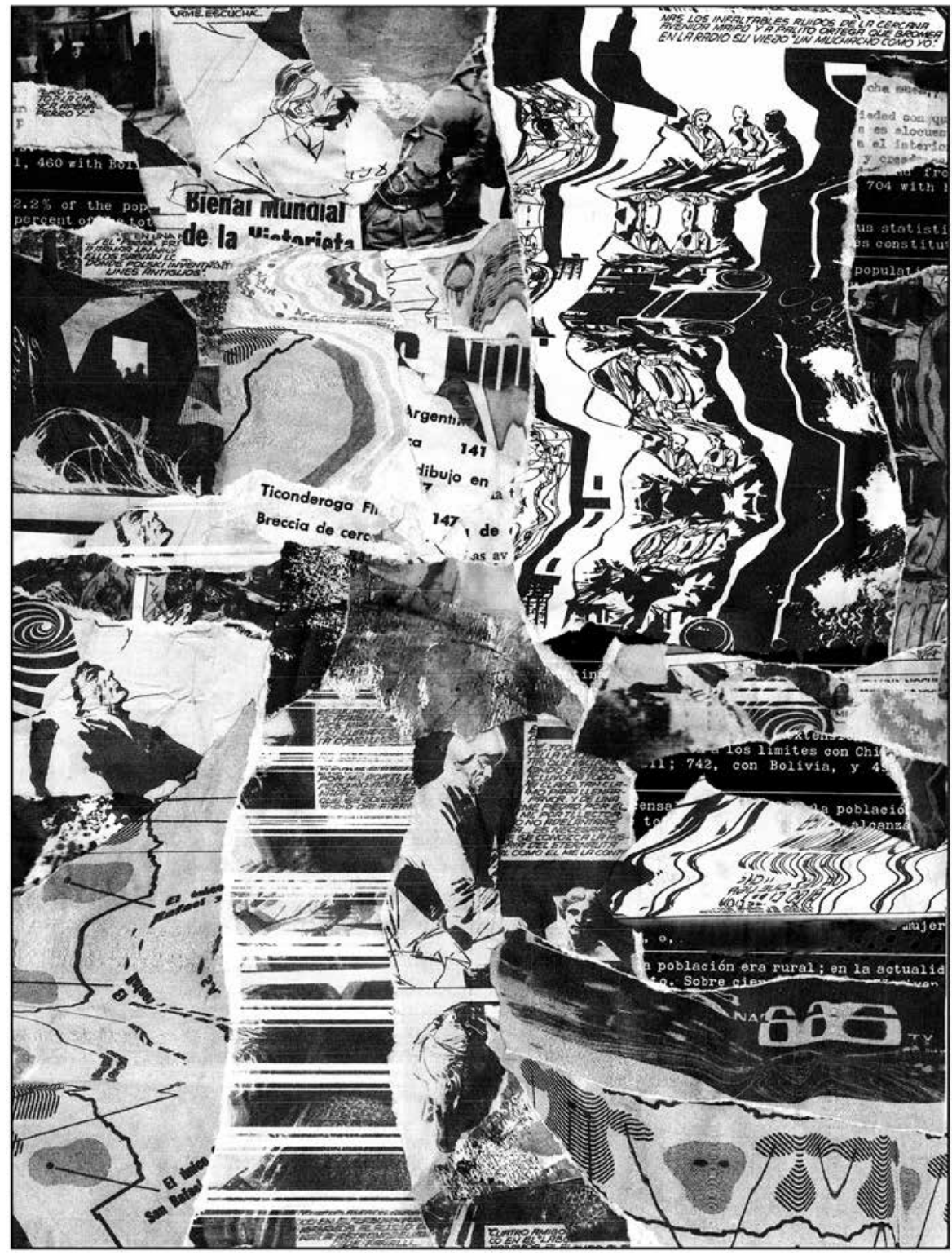




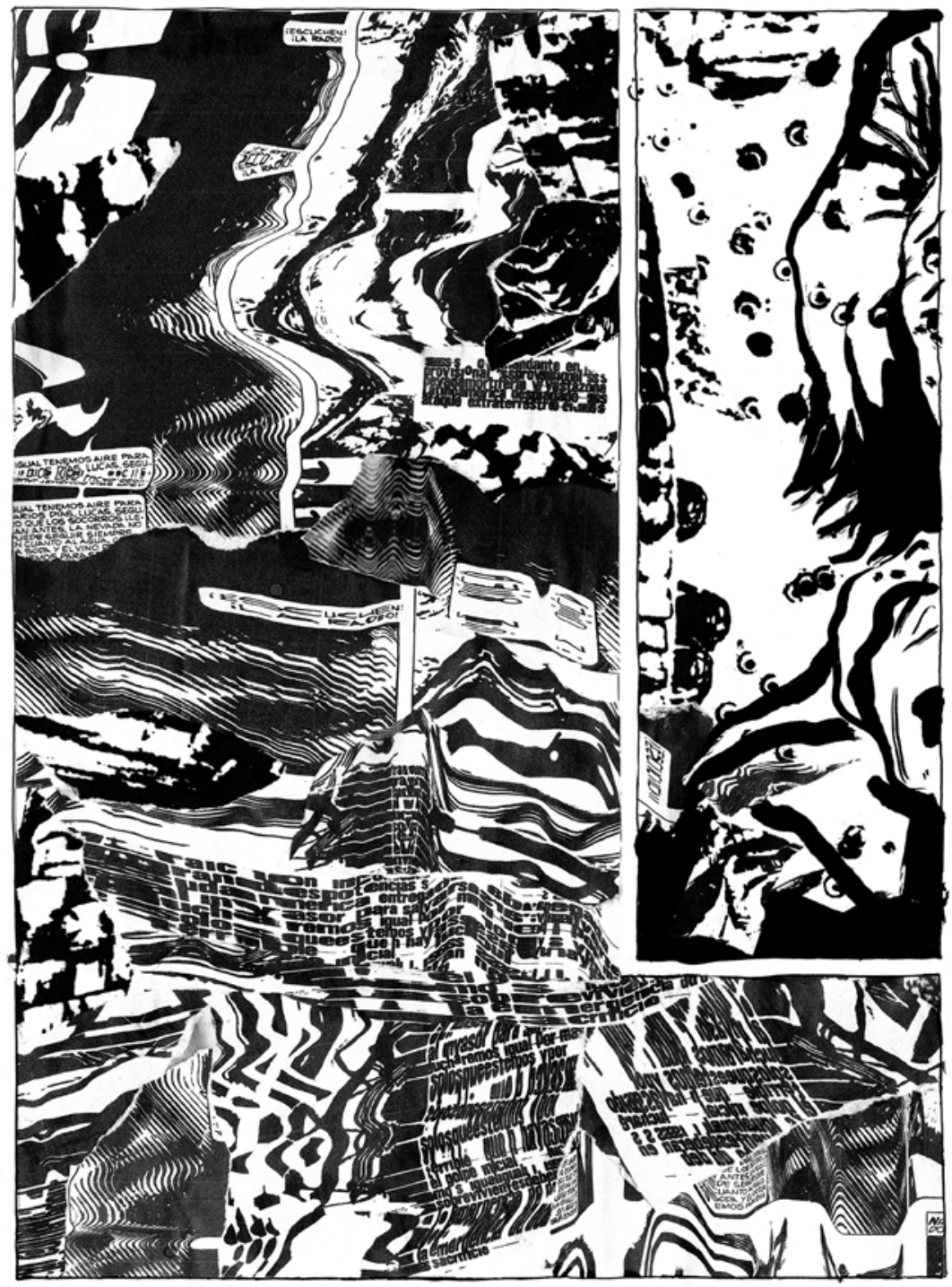




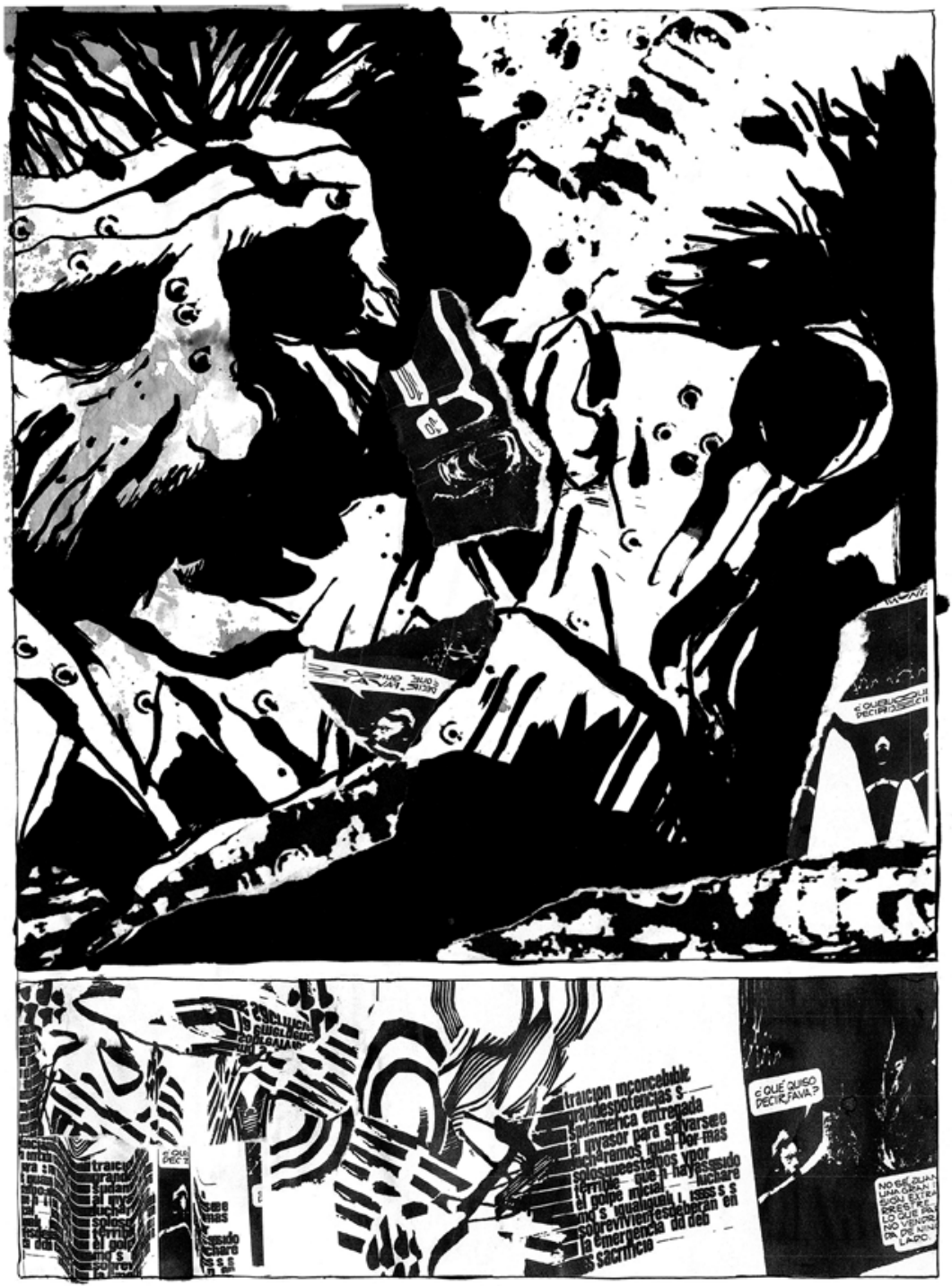



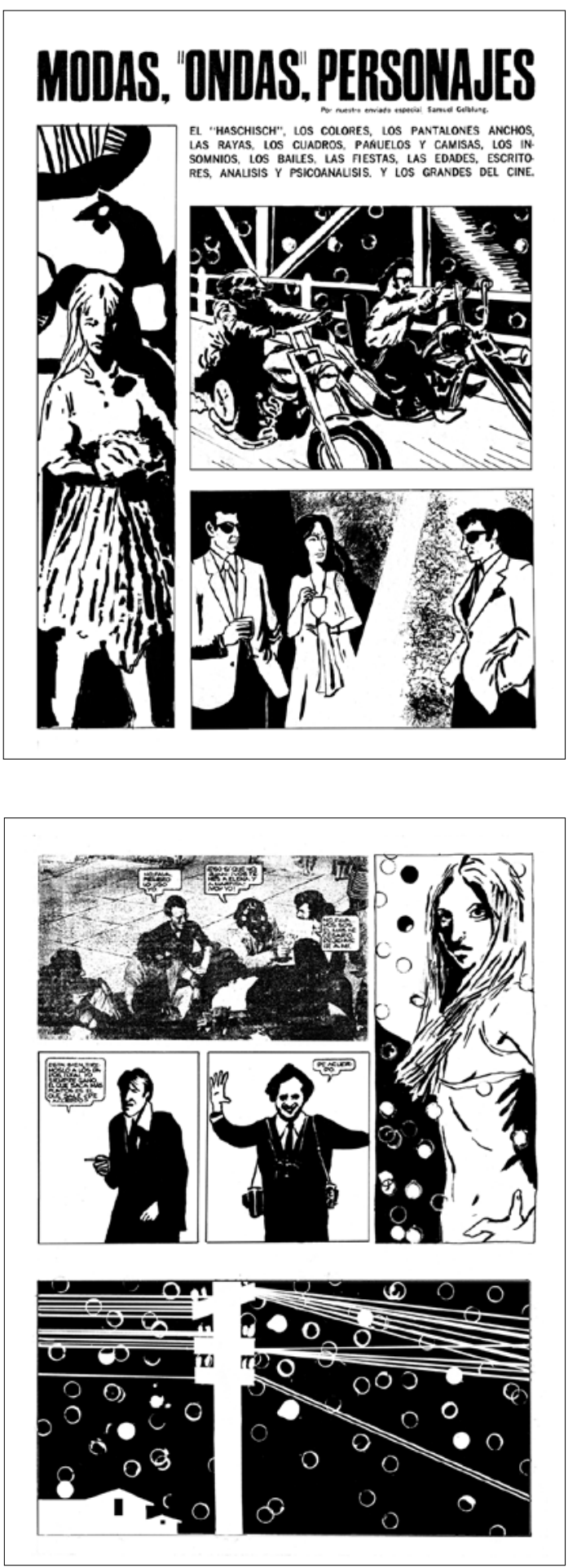

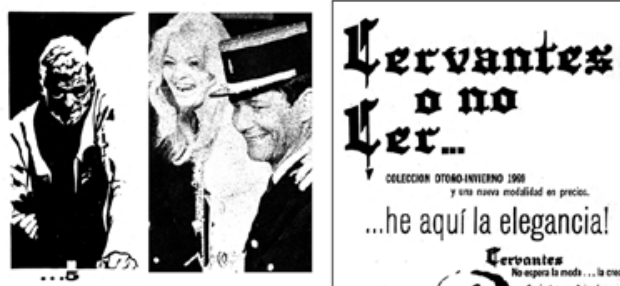
11 110

4er...

cecucoser orosoimano :

...he aquí la elegancia!
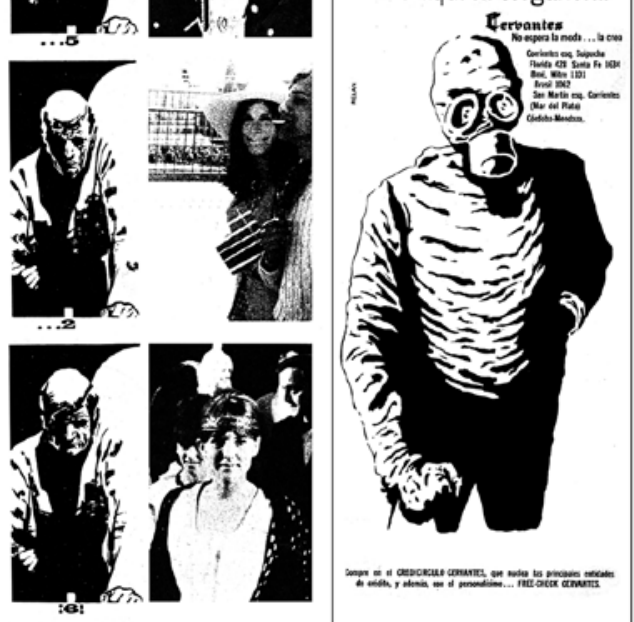

Cuando su personalidad está en juego...

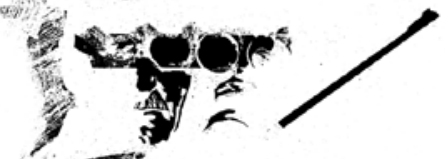

\section{NOEVO}

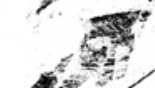

\section{d)}

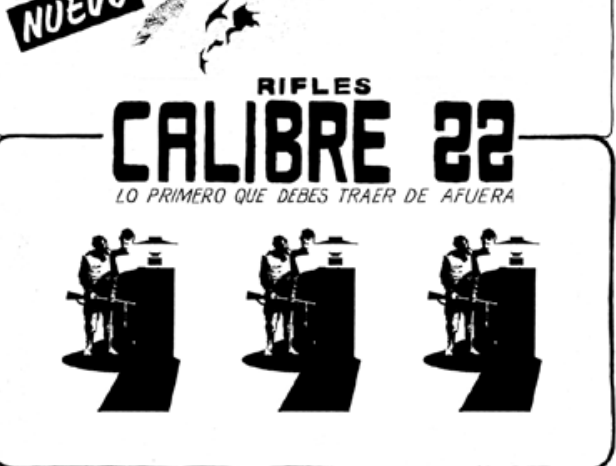




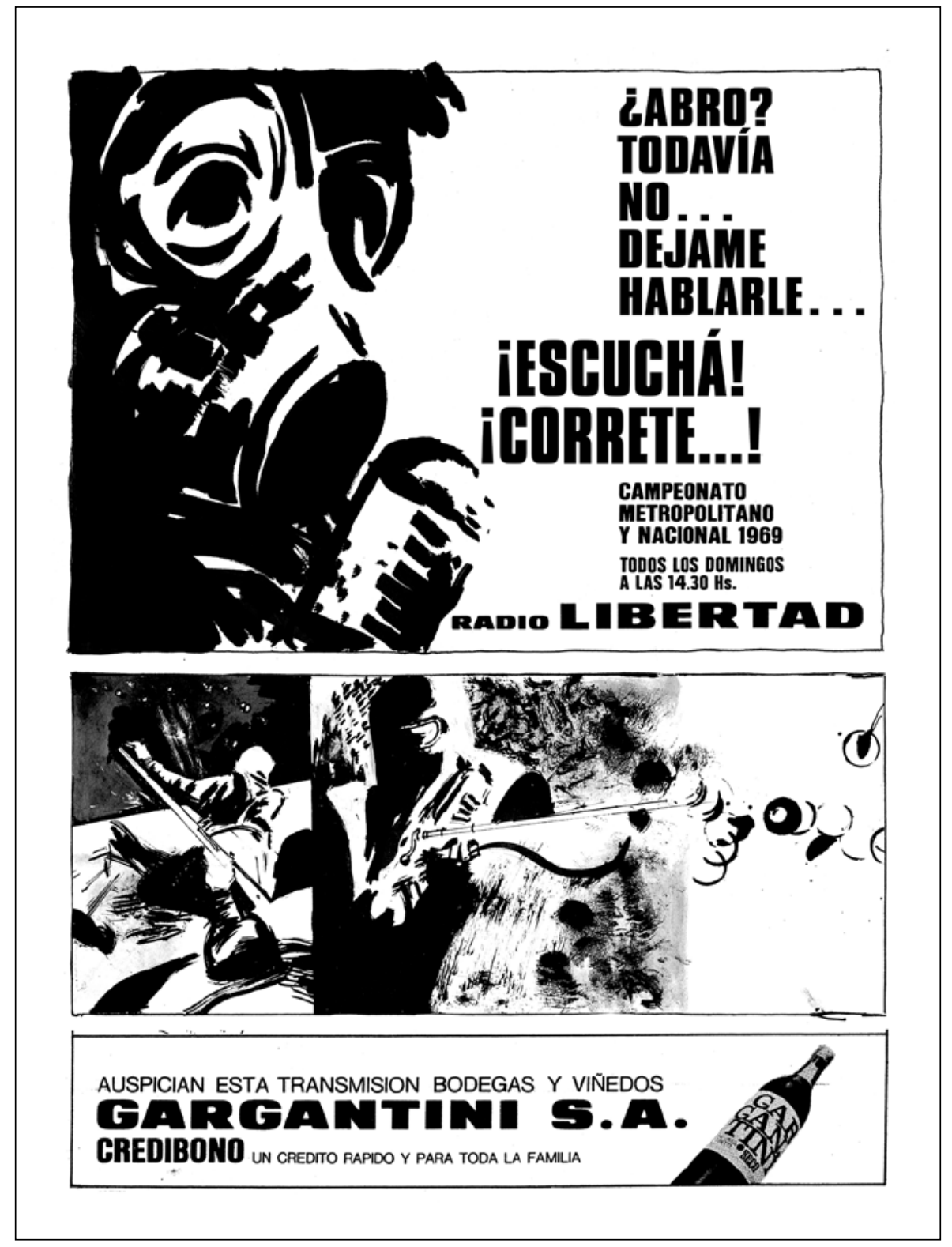



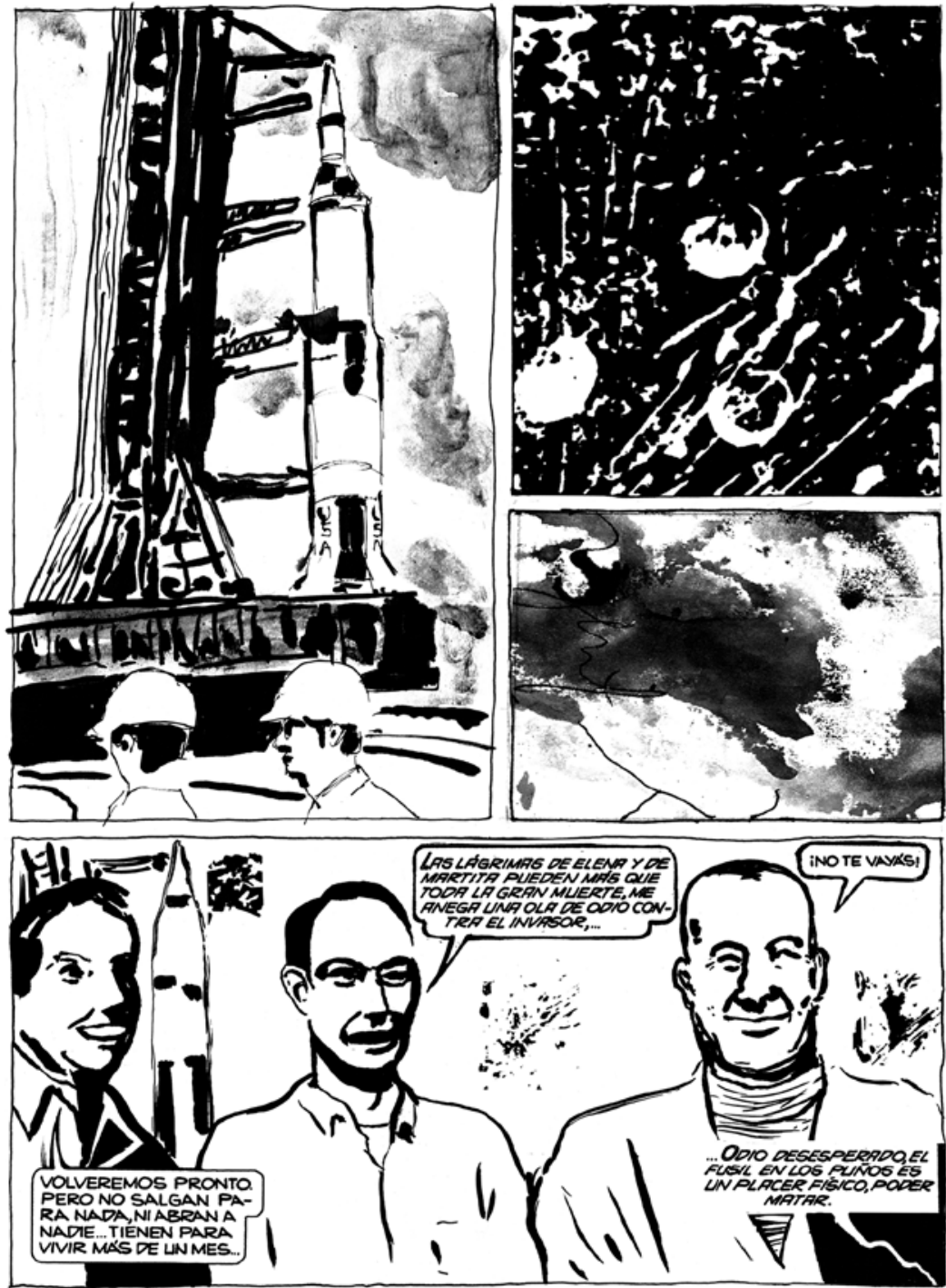


\section{Antes, el fusil en los puños era una insensatez total.}

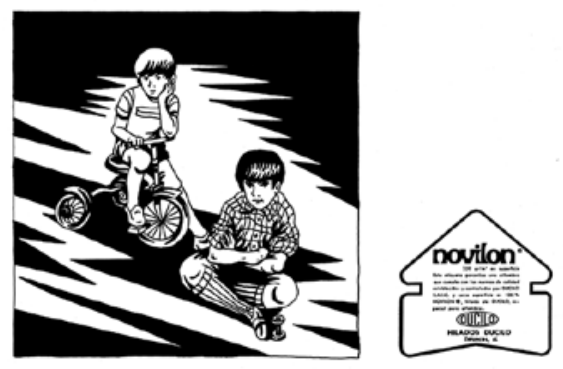

\section{Ahora, en cambio, optó por la acción contra el invasor.}

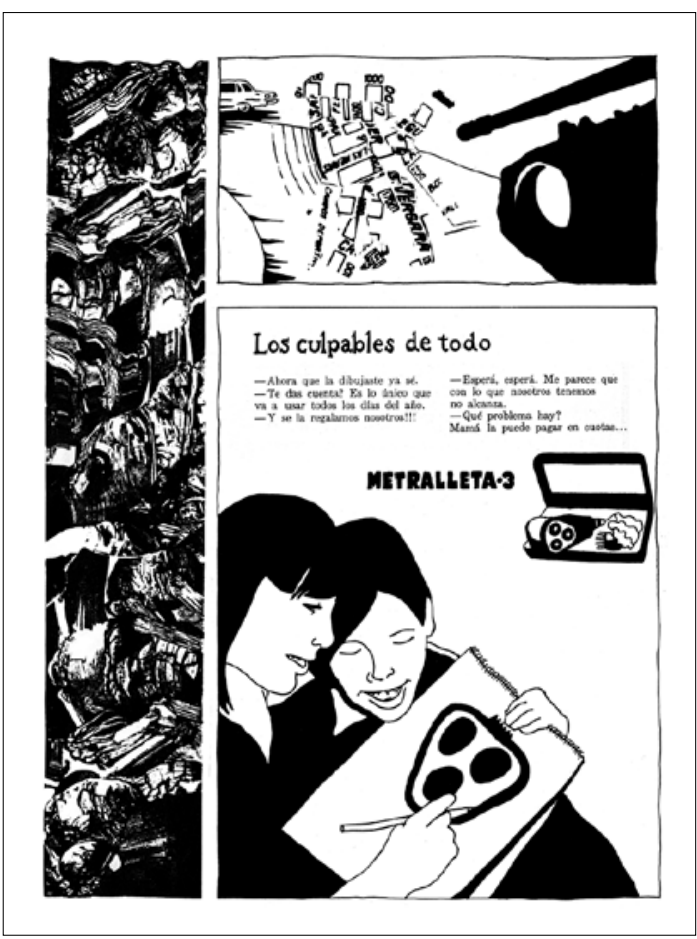




\section{$1 / 2$ metro $^{2}$}

\section{(O menos.Sobre eso se apoya la seguridad de su familia.)}

Un quejido desgarrador, Franco se desmorona, apenas si lo sostienen los hombres-robot... E1 "Mano" se acerca...

Una treta de Franco... Golpea y derriba al "Mano". Privados de guía, los hombre-robot no atinan a nada. Franco se libera, otra vez nos ponemos los cascos... y escapamos. Dejamos una granada bajo el teclado de mando, y nos llevamos al "Mano", bien envuelto para que no lo toquen los copos: lo queremos vivo, en él estaran, seguro, las claves de la invasión. No vamos lejos: la noche se enciende, naves aéreas nos buscan con sus reflectores, cascarudps y hombres-robot por todas partes. Nos refugiamos en una casa, en la cocina, ningún copo llego hasta alli. ¡E1 "Mano" esta reaccionando!

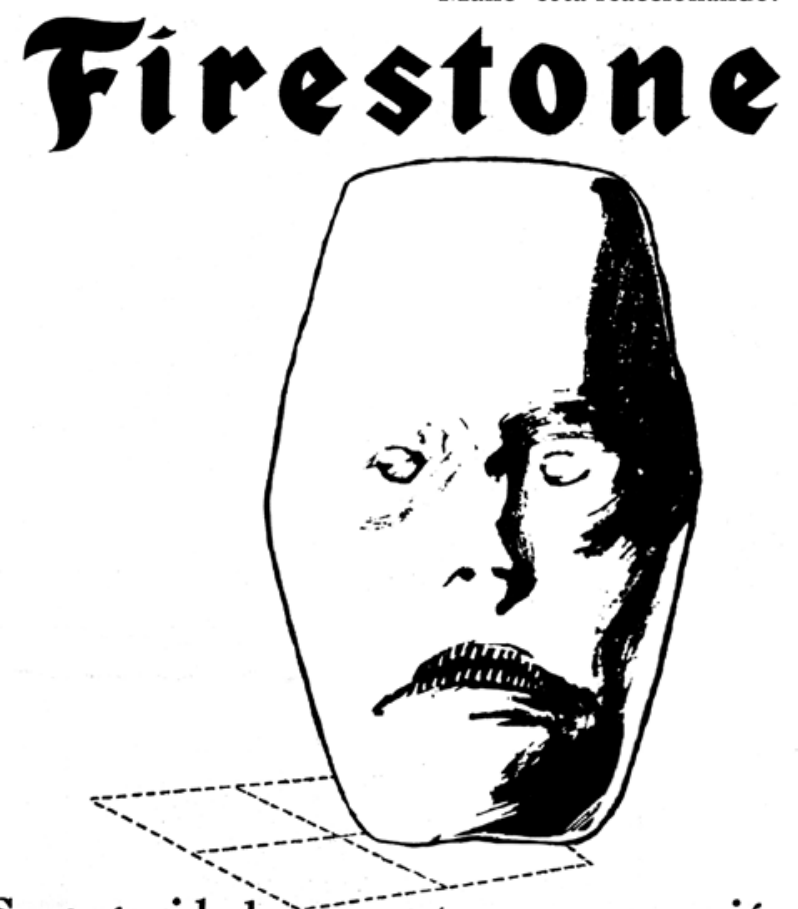

Su seguridad ès̄ nuestra preocupación. 